\title{
NIETZSCHE DESPUÉS DE MAYO DEL 68
}

\section{NIETZSCHE AFTER MAY 1968}

\author{
Elena NÁJERA* \\ Universidad de Alicante
}

Resumen: A partir del legado filosófico de Mayo del 68, el artículo se centra en el debate sobre el individualismo contemporáneo tomando como hilo conductor el pensamiento de Nietzsche. Este hilo atraviesa tanto el planteamiento antinietzscheano elaborado por Ferry y Renaut como el nietzscheanismo de izquierda que defiende Onfray, rastreándose así mismo en los enfoques neonihilistas de Glucksmann y Lipovetsky. El pretexto del recorrido es una cita de Así hablo Zaratustra que aparece entre las pintadas que ilustraron las paredes parisinas en la emblemática fecha: "Es preciso tener todavía caos dentro de si para poder dar a luz una estrella danzarina". El análisis de las dos metáforas que vertebran la frase -caos dentro de sí y estrella danzarina- y la búsqueda de su reflejo sesentayochista permite situar las posiciones de estos autores y considerar la capacidad moral que le conceden al individuo.

Palabras Clave: Nietzsche, Mayo del 68, individualismo, nihilismo, nietzscheanismo francés.

Aвstract: From the philosophical legacy of May 1968, the paper focuses on the debate on contemporary individualism using Nietzsche's thought as the guiding thread. This thread is present in both the anti-Nietzschean approach proposed by Ferry and Renaut and the left-wing Nietzscheanism defended by Onfray, and can also be traced

\footnotetext{
${ }^{1}$ Este trabajo ha sido realizado en el marco del Proyecto $\mathrm{I}+\mathrm{D}+\mathrm{I}$ «Gobierno de sí y políticas de la subjetividad en el contexto de la crisis de la racionalidad neoliberal» (FFI2016-76856-R), financiado por el Ministerio de Economía y Competitividad del Gobierno de España.

* Profesora Titular de Filosofía, Departamento de Humanidades Contemporáneas, Facultad de Filosofía y Letras de la Universidad de Alicante, Campus de San Vicente del Raspeig Ap. 99, E-03080 Alicante. E-mail: elena.najera@ua.es
} 
in the neo-Nihilist approaches of Glucksmann and Lipovetsky. The pretext for this is a quote from Thus Spoke Zarathustra which appeared among the graffiti covering Parisian walls at the time: 'One must still have chaos in oneself to be able to give birth to a dancing star.' An analysis of the two metaphors - 'chaos in oneself' and 'dancing star' - lending meaning to the phrase and the quest for its reflection in the events of May 1968 make it possible to identify the positions of the aforementioned authors and to consider the moral capacity granted to the individual.

Keywords: Nietzsche, May 1968, individualism, nihilism, French Nietzscheanism.

\section{Introducción}

Tras un nuevo aniversario señalado por lo redondo de la cifra, medio siglo, la reseña filosófica de Mayo del 68 sigue presentando dificultades. El acuñado rótulo de "pensamiento del 68" no ha dejado de eludir en ningún caso la polémica. Cabe recordar que constituye el título del volumen que firmaron L. Ferry y A. Renaut en 1985 y que alentó una inacabada discusión no sólo a propósito del antihumanismo en torno al que se reunía en sus páginas a ciertos autores, sino también sobre la posibilidad de cerrar un programa de antecedentes o de ideas congénitas a ese acontecimiento o claramente expresivas del mismo ${ }^{2}$. Hay una nómina estable de filósofos contemporáneos vinculada a ese epígrafe. M. Foucault, J. Derrida, J. Lacan y P. Bourdieu se correlacionan con él frecuentemente - protagonizan así mismo el libro citado-, a pesar de que ninguno se sintió identificado ni directamente interpelado por lo que estaba ocurriendo ${ }^{3}$. También L. Althusser, H. Marcuse y quienes acompañaron los movimientos estudiantiles y obreros -M. Blanchot, G. Deleuze, S. de Beauvoir, J.-P. Sartre...- engrosan la lista de referencias. Y, sin duda, puede apreciarse un aire de familia entre el diario de Mayo del 68 y algunos de los textos de estos y otros autores. Sin embargo, su denominador común dista de ser evidente y el trasfondo filosófico del escenario se resiste al dibujo continuo y homogéneo.

A la vez, se plantea la cuestión de la historia efectual de esta rotunda fecha que sufre la tensión hermenéutica propia de lo simbólico, sometiéndose

2 Ferry et Renaut, 1985. Una discusión en torno a esta obra se ofrece, por ejemplo, en el volumen colectivo VV. AA., 2008. Véase también Morin, 2008. Y para una visión panorámica de la cuestión, puede consultarse el trabajo de Bello, 2010.

3 Véase al respecto Lecourt, 1999: 38ss. y Ross, 2008: 362ss. 
periódicamente a un proceso de revisión y actualización. En este plano su rendimiento, lejos de la univocidad, es amplio y se compagina con una diversidad de interpretaciones cuyo bosquejo completo desborda el espacio de este artículo. En él se propone una cartografía deliberadamente parcial, acotada en torno a dos claves que se implican mutuamente y que centran la atención en un nombre todavía no aludido.

En primer lugar, se va a asumir como campo de estudio la vinculación de Mayo del 68 al complejo y vasto debate en torno a la construcción contemporánea de la subjetividad y, más concretamente, en torno al perfil que adquiere el individuo en las sociedades occidentales de cambio de siglo. Este es el motivo que vertebra la monografía de Ferry y Renaut, quienes ven en los planteamientos filosóficos que, a su entender, amparan este acontecimiento el síntoma de un individualismo incompatible con la articulación de una intersubjetividad productiva en un sentido democrático. Pero, del mismo modo, es el motivo de aproximaciones en sentido contrario como la de M. Onfray, que reivindica este momento como una determinante contribución a una ética libertaria desde la que repensar la autonomía. En estos dos extremos y también en las lecturas individualistas que proponen los denominados Nuevos filósofos, A. Glucksmann y G. Lipovetsky, late una constante que proporciona la segunda clave: el diálogo que entablan todos estos autores con Nietzsche y su compartido interés en evaluar el diagnóstico epocal de nihilismo que se declara en su obra.

Esta confrontación atraviesa La pensée 68, que contiene un capítulo sobre el nietzcheanismo francés - dedicado casi íntegramente a Foucault, con alusiones a Deleuze-, y todavía se hace más evidente cuando se aprecia que este libro encuentra una secuencia coherente en el volumen colectivo que coordinaron Ferry y Renaut en 1991 y que titularon de una manera explícita Pourquoi nous ne sommes pas nietzschéens. Onfray, por su parte, a la contra, aplicándose a poner en valor la adscripción que estos autores reprueban, reclama expresamente a propósito de esa fecha un nietzscheanismo de izquierda. Y un nietzscheanismo de la tendencia opuesta, de derecha-podría decirse con una licencia terminológica que luego habrá ocasión de matizar- es el que palpita en la exégesis neonihilista que proponen Lipovetsky y Glucksmann con la intención de rectificar el entusiasmo que ellos mismos vivieron en primera persona. Mayo del 68 muestra, así pues, diferentes inflexiones nietzscheanas que modulan una de las secciones del debate reciente en torno al individualismo. 
El recorrido comenzará atendiendo a este hilo conductor nietzscheano -que tiene más fibras que las contadas por Ferry y Renaut-. A su adecuada reconstrucción quiere contribuir de manera original este trabajo evidenciando, por una parte, que dicho hilo formaba parte esencial del tejido intelectual francés de la década de los sesenta y alegando, por otra, que se prolonga en las décadas posteriores sobreviviendo a la suerte de Mayo del 68. Lo primero se visibilizó en los muros parisinos. A modo de lema, declaración de intenciones o simplemente expresión espontánea y casual, todo lo que fue inscribiéndose en ellos ha acabado dando forma a la memoria colectiva de ese acontecimiento e integrándose en su relato. A las pintadas se recurrirá a lo largo de estas páginas buscando anclaje tras haber encontrado al mismo tiempo entre ellas el pretexto justo, pues el trozo de pared que se va a enfocar estratégicamente luce una frase de Así habló Zaratustra: "Es preciso tener todavía caos dentro de sí para poder dar a luz una estrella danzarina”. El análisis de las metáforas que la articulan y la búsqueda de su reflejo sesentayochista permitirá ordenar el debate entre los autores citados, pero profundizar también más allá de esta fecha y sus sucesivas conmemoraciones en la reflexión sobre el individuo y su capacidad de resistencia al poder.

\section{EI hilo conductor nietzscheano}

Sin poder reducirse a Nietzsche las múltiples líneas de inspiración, de investigación y de lectura de la década de los sesenta, sí puede considerarse que su filosofía era una de las que circulaba recurrentemente por las aulas y las calles parisinas en la primavera del 68. En 1964 se había celebrado en Royaumont un congreso internacional sobre el pensador alemán que contó con la intervención de lectores incansables de sus escritos como Vattimo, Klossowski, Löwith, Deleuze, Foucault... Sus actas se publicaron en 1967, recogiendo en su introducción la presentación de las jornadas que hizo M. Gueroult y que situaba el propio pensamiento de Nietzsche dentro del esquema alegórico del discurso "De las tres transformaciones" con el que se abre Así habló Zaratustra. De esta suerte, su propuesta se asumía ciertamente como una maniobra de ruptura frente al alienante deber impersonal con el que cargaba simbólicamente el camello, que personificaba la postración ante el peso de la tradición, las convenciones y los argumentos de autoridad. Pero su destino final se proyectaba en el paso de la figura del león a la del niño, mostrándose, por lo tanto, bajo el signo de una 
nueva afirmación (VV. AA., 1967: 9)4 . Junto a su volumen crítico -de destrucción-, lo que se ponderaba fundamentalmente era su potencial para introducir un orden diferente, innovador.

Deleuze había publicado también en 1967 su Nietzsche et la philosophie, una monografía de gran difusión que Foucault, por ejemplo, reconoce como influencia fundamental en Un diálogo sobre el poder (Foucault, 2004: 31). En ella, invocándose también el antedicho pasaje de Así habló Zaratustra, se insiste en el sentido positivo de la transvaloración o transmutación propuesta por este pensador que implica hacer de la negación algo activo al servicio de una creación que queda apostillada como dionisiaca. La constelación de Dionisos es la del "sí del niño juguetón, más profundo que el no sagrado del león” (Deleuze, 1986: 269). Esto se traduce, a juicio de Deleuze, en que el sentido de lo que formula Nietzsche radica en "que lo múltiple, el devenir, el azar, sean objeto de afirmación pura” (Deleuze, 1986: 274). Se trata de encontrar en su filosofía argumentos para restituir el dominio subversivo de las diferenciaciones y lo fragmentario y para desvincularse, en consecuencia, de las exigencias de la mediación dialéctica hegeliana -aspecto al que se volverá después-. La conclusión que subraya es que "la afirmación de lo múltiple" pasa a ser el nuevo "postulado especulativo", así como "el placer de lo diverso", el "postulado práctico" (Deleuze, 1986: 274).

Y esta visión que valora la eficacia transformadora del pensamiento nietzscheano es la que se explota así mismo en la interpretación de Lefebvre, uno de los intelectuales que participó activamente en Mayo del 68 y que no dejó de escribir y reescribir sobre el autor alemán a lo largo de su trayectoria 5 . En 1939 ya le había dedicado un libro interesado en desmarcarlo de las interpretaciones fascistas que abundaron en la época de entreguerras (Lefebvre, 1939). Y en textos posteriores incide en su rehabilitación distinguiendo entre las diferentes lecturas a las que se ha prestado su obra. En Hegel, Marx, Nietzsche ou le royaume des ombres, de 1975, recapitulaba apuntando que su presencia en Francia había dado como resultado una renovación de la filosofía en el preciso sentido de que "mientras que bajo la influencia hegeliana, el filósofo profesional se convierte en servidor (servil) de la política, el filósofo de filiación nietzscheana se pronuncia contra el poder, sea cual fuere" (Lefebvre, 1976: 186). Y, teniendo este contraste en cuenta, si bien niega que pueda hablarse estrictamente de un "nietzscheísmo" teórico como corpus compacto, reconoce, en cambio, el efecto plural de "una

4 Véase la reseña del congreso hecha en Descombes, 1991: 110.

5 Véase Hess, 1988. Puede consultarse también Bantigny, 2018: 331ss. 
práctica nietzscheana": una práctica poiética "que valora lo vivido en detrimento de lo concebido y de lo percibido, supervalorados por el Logos occidental" (Lefebvre, 1976: 238). De acuerdo con esto último, Lefebvre recurre así mismo a lo dionisíaco para trazar el campo semántico de este enfoque vitalista al que le concede capacidad subversiva frente al orden hegemónico. Como recalca en el capítulo que le dedica a Nietzsche en La fin de l’histoire, de 1971: “¿Hace falta agregar que Dioniso era el amigo y el dios de los esclavos y las mujeres, no sólo de los campesinos y provincianos semibárbaros de Tracia?” (Lefebvre, 1973: 90).

Los apuntes dados permiten apreciar una parte medular de la estructura del nietzscheanismo francés que se gesta en la década de los sesenta y marca el clima filosófico de las posteriores. En ella encaja el pretexto mural de estas páginas que mantiene el registro dionisíaco cultivado por Deleuze y Lefebvre. En las escaleras del hall del Teatro del Odéon se reprodujo la frase ya anticipada: "Il faut porter encore en soi un chaos pour pouvoir mettre au monde une étoile dansante (Nietzsche)" (Besançon, 1968: 115) ${ }^{6}$. Cabe recordar que la matriz de la cita es el célebre prólogo de Así habló Zaratustra, un libro singular en la producción nietzscheana centrado en salvar la posibilidad del Übermensch de entre el nihilismo pasivo que encarna la figura antitética del último hombre. La pintada funciona como una actualización que da inmediatamente el pie para valorar la impronta de este pensador en Mayo del 68. Es un enunciado rico en sí mismo -citado también por Deleuze en su monografía (Deleuze, 1986: 46-47) - que invita a recrearse en su fondo poético y a explorar su lugar y su resonancia intramuros, dentro de la propia obra nietzscheana ${ }^{7}$. Ello propiciaría un enlace múltiple a los conceptos de voluntad de poder, devenir, eterno retorno, amor fati, lo trágico... Pero, de acuerdo con el objetivo de este trabajo, los siguientes dos epígrafes se ceñirán al análisis de las imágenes de caos y estrella danzarina tal y como se correlacionan en el fragmento tratando de recuperar tanto su proyección sesentayochista como su eco en la reflexión posterior sobre el individualismo. Ambas metáforas son complementarias y contienen una propuesta interesada en la formación de una subjetividad activa y creativa que se sustenta sobre la afirmación de la inocencia del devenir. Contra la seducción de los marcos teleológicos de progreso y también contra la perplejidad en la que cae el último hombre que no ve la oportunidad

6 El texto original es: "man muss noch Chaos in sich haben, um einen tanzenden Stern gebären zu können” KSA 4-19. Los textos en alemán de Nietzsche se referirán según Nietzsche (1999) con la abreviatura KSA señalándose volumen y página. Las citas y frases de las paredes de Mayo del 68 se reproducen de acuerdo a la recopilación de Besançon (1968).

7 Es lo que hace Rivera de Rosales (2012) en el marco de la lectura de Así habló Zaratustra. 
de acuñar otros valores, el dictum de Zaratustra quiere insistir en la posibilidad de incorporar diferencia y novedad en la propia visión del mundo.

\section{El caos dentro de sí}

La invocación del caos es recurrente en el pensamiento de Nietzsche. En un fragmento póstumo se apunta "Chaos sive natura" absolutizándose la hechura indefinida del devenir, que no puede eludir, en consecuencia, ni la multiplicidad de posiciones ni la confrontación entre ellas (KSA 9-519) ${ }^{8}$. Lo humano no es para este autor un plan acorde a una finalidad trascedente $\mathrm{o}$ a una providencia, sino un espacio entregado a un juego inestable de influencias y de resistencias. Partiendo de la frase de Así habló Zaratustra que nos ocupa, la apelación al "caos dentro de sî", remite de una manera más concreta a la crítica dirigida contra el yo - Ich- de la tradición moderna que se postula como una entidad sustancial y autotransparente. Se quiere impugnar así la concepción del sujeto elaborada en la secuencia filosófica que va de Descartes a Kant y que alega su desvinculación con respecto a toda circunstancia particular con la pretensión de reproducir unas normas epistemológicas y éticas unívocas y universales.

Frente a este paradigma, Nietzsche propone avanzar hacia una comprensión hermenéutica de la subjetividad que formula recurriendo al término mismidad o si mismo -Selbst-. Este se hace cargo de una realidad compleja y dinámica vertebrada por la "multiplicidad", "la constante transitoriedad y fluctuabilidad" (KSA 11-650). Su identidad no es más que el movimiento narrativo de sus experiencias y el equilibrio contingente que entre ellas se establezca: una "síntesis prodigiosa de seres vivientes y de intelectos" o, en otras palabras, una diversidad de "fuerzas" o de "«voluntades de poder»" voluntad de poder interpreta", señala el filósofo, y "la interpretación es un medio en ella misma de llegar a ser dueño (Herr) de algo" (KSA 12-139-140). Así pues, en continuidad con la ausencia de un Orden, el momento afirmativo o creativo en el que se resuelve la propia mirada, cuando se dirige tanto hacia dentro como

\footnotetext{
8 Véase también Nietzsche, 2011: 202, KSA 3-468, donde puede leerse "el carácter total del mundo por toda la eternidad no es más que caos; aunque no en el sentido de una ausencia de necesidad, sino de una ausencia de orden, organización, de forma, de belleza, de sabiduría y de todo cuanto tenga que ver con nuestra estética antropomorfa".

9 Véase los fragmentos 37 [4] de junio-julio de 1885, KSA 11-577, 34[123] de abril-junio de 1885, KSA 11-461 y 1[58] de otońo de 1885-primavera de 1886, KSA 12-25.
} 
hacia fuera, implica siempre la imposición de un punto de vista sobre otros y queda, por lo tanto, abocado a la parcialidad y al perspectivismo. La silueta con la que se traza el Selbst, al igual que ocurre con el significado del que se dota al resto de una realidad que está invariablemente en curso, es relacional y relativa. Para Nietzsche el conocimiento ha de rendirse, en resumidas cuentas, a la pluralidad de enfoques y la moral, lejos de apelar a una abstracta razón de corte igualitarista, ha de hacerlo al derecho a la diferencia.

Ferry y Renaut localizan en Mayo del 68 un momento decisivo de este cambio de sensibilidad ética que responde, a su entender, al desvío que toma la autocomprensión del individuo contemporáneo con respecto a la lógica del sujeto característica de la modernidad. La cuestión para ellos es que esta última figura, que representa lo común y sostiene la aspiración a un punto de vista universal, se ve progresivamente sobrepasada por la primera. Esta quedaría definida por su desinterés e independencia con respecto a lo social, desembocando en una suerte de "individualismo sin sujeto" que dificulta la confección de la urdimbre intersubjetiva (Ferry et Renaut, 1985: 122; Renaut, 1993: 121ss.; Renaut, 1998: 55-77). La fijación de este yo refractario a la moralización tendría uno de sus principales capítulos en la obra de Nietzsche según Ferry y Renaut. Y en ella, al margen de la valoración negativa que hacen estos autores y en cuya parcialidad luego se insistirá, se miden ciertamente dos maneras de pensar el campo de acción del individuo ${ }^{10}$. Por una parte, se pone en tela de juicio el planteamiento democrático que, según el filósofo del martillo, responde a un tipo de ser humano que, no siendo capaz de asumir el riesgo de la idiosincrasia, necesita asegurarse que "está siempre inter pares", entre semejantes que comparten los mismos objetivos (KSA 11-642). Este individuo débil -compatible con el último hombre- se manifestaría, por ejemplo, en el sujeto del socialismo y del anarquismo, que representa a "todos los particulares contra la totalidad" conformando una masa homogénea que quiere fundamentalmente desligarse de las instituciones, "se trate del estado o de la iglesia" (KSA 12-502-503). Este margen de autonomía resulta completamente insuficiente en tanto y cuanto recoge una serie de derechos abstractos e iguales que, justamente por ello, impiden el desarrollo de programas morales propios. Tal descuido de la singularidad reduciría la voluntad de poder a su mínima expresión.

10 Sobre estos dos individualismos, véase Renaut, 1989: 244ss. Puede consultarse Ferry et Renaut, 1991: 129ss. 
Para Nietzsche, en consecuencia, la democracia contemporánea, respondiendo a las necesidades de las sociedades industrializadas, genera masivamente individuos impersonales en situación de heteronomía. Ello se traduce además en la generalización de una educación que se concibe como una instrucción técnica, provechosa y "rápida" que uniformiza y disciplina a sus beneficiarios obligando a desconfiar de todo saber que fabrique solitarios y "que coloque sus fines más allá del dinero, que consuma mucho tiempo" (Nietzsche, 2000: 53-54, KSA 1-581-583). Con este planteamiento se corresponde un ansia de seguridad, el "anhelo de querer tener de modo absoluto algo firme", que no trasluce sino la "pereza" para pensar por uno mismo (Nietzsche, 2011: 338-341, 90-91, KSA 3-667-668, 373). La "mejora" de la humanidad prometida por la ilustración y expresiva del espíritu de la modernidad quedaría para Nietzsche compendiada en el término "doma" (Zähmung) y se entendería, por lo tanto, como la producción del "mejor animal doméstico (Hausthiere)" (Nietzsche, 1996: 72, KSA 6-99; Nietzsche, 1994: 240, KSA 4-214). Buscando la resonancia sesentayochista, en las calles parisinas se compartió en buena medida esta crítica al sistema educativo, siendo culpada la universidad de atrofiar el criterio individual -de "producir generaciones de castrados" (Besançon, 1968: 163) ${ }^{11}$ - conformándolo al statu quo.

Cabe señalar además que la inspiración nietzscheana se desarrolla en este punto de una manera explícita a través de la obra de Foucault. En la Histoire de la folie à l'âge classique, publicada en 1961, se acusaba en el proyecto moderno la institucionalización de la racionalidad -de una cierta comprensión de la misma- como norma, lo que implicaba la marginación a efectos filosóficos, pero también ético-políticos, de lo que no encajaba en ese campo. Bajo esta sospecha, el patrón del sujeto cartesiano se revelaba como un dispositivo de uniformización y de control y, frente a la ilusión de un sujeto soberano que puede desvincularse de sus circunstancias, se señalaba su sujeción al poder. Según Foucault, este se despliega además ampliamente por todo el tejido de la sociedad de una manera múltiple, difusa y sutil, sirviéndose de una pluralidad de instancias -visibles y no visibles- de jerarquía, control, vigilancia, prohibición, coacción... (Foucault, 2004: 30ss.). El individuo no puede pensarse, por tanto, como absolutamente autónomo porque no puede constituirse al margen de la extensa red de las prácticas normativas y fuera de las líneas de clasificación y, por tanto, de inclusión/ exclusión que estas trazan.

11 "L'urbanisme de la Sorbonne a produit les générations de chatrés que nous connaissons". 
Sobre el trasfondo de esta filosofía de la sospecha, la imagen del caos tendría un reflejo preciso en el antinormativismo que recorre el relato de Mayo del $68^{12}$. Uno de sus capítulos principales se detiene sin duda en la contundente oposición -se autopresenta como rabiosa ${ }^{13}$ - que quienes salieron a las calles expresaron frente al régimen que pautaba la existencia de los individuos de acuerdo con los intereses del capital, del estado y -también- del patriarcado-. Onfray habla en este sentido de la "metafísica de la destrucción" que se activa en esta fecha contra el trípode reaccionario Trabajo-Familia-Patria y que aspira a suspender los argumentos de autoridad que emanan de estas instituciones (Onfray, 2011: 151). Y si hay una pintada de entre las que ilustraron las calles parisinas que se ha erigido en consigna de su espíritu es la de "Prohibido prohibir" que lució significativamente en los muros de la Sorbona (Besançon, 1968: 42) ${ }^{14}$. La facultad de Medicina se preguntaba así mismo a propósito de la función opresiva que ejercían solidariamente las instancias amo/profesor, dios, padre: "Qu'est-ce qu'un maître, un dieu? L'un et l'autre sont une image du père et remplissent une fonction oppressive par définition" (Besançon, 1968: 145).

La cuestión es que este tono antinormativo que se percibe en el caos al que apelaba Zaratustra debería servir para generar un clima de innovación y afirmación. Dicha metáfora evoca la negación del orden gregario convencional, pero también, enlazando con las lecturas de Deleuze y Lefebvre, el reconocimiento dionisíaco -y antihegeliano- de la pluralidad y la diversidad. De acuerdo con el diagnóstico que hace Nietzsche, y que puede proyectarse en Mayo del 68, a nuestro alrededor hay "viejas tablas rotas y también tablas nuevas a medio escribir" (Nietzsche, 1994: 273, KSA 4-246). Este momento de tránsito sería el propicio para avanzar hacia esa otra concepción del individuo -superadora de la que han gestionado las democracias industrializadas- que el autor alemán contempla en su obra. La meta del caos dentro de síha de ser, en definitiva, una estrella danzarina que ilustre los valores de esa subjetividad alternativa.

12 En este punto incide la crítica de La pensée 68, pp. 138ss.

13 “Enragez-vous!", podía leerse en varias paredes. Véase Besançon, 1968: 91.

14 La pintada completa es "Interdit d' interdire. La liberté commence par une interdiction: celle de nuire à la liberté d'autrui". 


\section{La estrella danzarina}

Esta imagen representa, efectivamente, un horizonte de superación del nihilismo en el que Nietzsche reivindica una versión del individuo que quiere dotar de sentido a una noción de autonomía comprometida con el derecho a la diferencia. Contando con el espacio hermenéutico del Selbst, propone para ello una ética que entrega a cada sujeto la autoridad para escribir su biografía. Se trata de ejercitar una "fuerza de autodeterminación, una libertad de la voluntad" que ha de preparar al yo -insiste metafóricamente- para "poder mantenerse sobre cuerdas y posibilidades ligeras y hasta para bailar al borde de abismos" (Nietzsche, 2011: 338-340, KSA 3-581-583). La evocación recurrente de la danza, al hilo siempre de la demanda de ligereza y equilibrio, subraya el contexto creativo, pero también frágil que ampara la inocencia del devenir. La subjetividad en primera persona del singular entraña para Nietzsche un esfuerzo y un riesgo ineludibles en la medida en que apremia a trazar un camino fuera de la comodidad de los lugares comunes y de la confortación de los marcos teleológicos. Por ello, contra cualquier pretensión de universalismo o abstracción, se exige que el propio deber, entendido como el ideal que cada cual se marque para autorrealizarse -para llegar a ser lo que se es, como se plantea en Ecce homo-, no se asimile al concepto de deber en general. Este sería una invitación a la impersonalidad, la jugada interpretativa de una voluntad de poder minimizada, incapaz de hacerse cargo del reto de la idiosincrasia.

Siguiendo el rastro de esta estrella danzarina, ahora cabe contrastar si la propuesta de Nietzsche se asume en la revisión de Mayo del 68 que hacen los autores emplazados. Según Ferry y Renaut, como ya se ha expuesto, hay una convergencia evidente entre dicha propuesta y la secuela de esta fecha, contribuyendo ambas al vaciamiento del contenido ético del individualismo contemporáneo y al desgaste de la vocación igualitarista y universalista -democrática- que tenía la figura del sujeto moderno. Así pues, tras el clímax antinormativo sólo quedaría, a su juicio, un terreno de inmoralidad que el discurso nietzscheano acentúa haciendo valer el registro del aristocratismo. Y, ciertamente, a él recurre el Selbst para conceptualizar una afirmación de sí que ha de cultivar el pathos de la distancia ${ }^{15}$. El monolítico antinietzscheanismo de Ferry y Renaut no permite, no obstante, apreciar que la intención del filósofo alemán es, como se recalcará al final, la de priorizar el sentido de la propia singularidad y no la de desmantelar lo común.

15 Es un tema abordado por Nietzsche en El Anticristo. Véase al respecto Nájera, 2018. 
Por otra parte, la convocatoria al caos abre otros escenarios, como el que vislumbran Lipovetsky y Glucksmann, quienes vivieron con entusiasmo Mayo del 68 para desmarcarse posteriormente de su presunto legado ${ }^{16}$. Los denominados Nuevos filósofos se dedican, en efecto, a corregir la primera impresión de ruptura reenfocando una mirada desencantada que cede al balance neonihilista. Para Glucksmann, la simbólica fecha evoca "una aventura incómoda, que no tiene lecciones unívocas ni da paso a un destino idéntico para todos" (Glucksmann, 2018: 92). Las llamadas a la liberación sexual, a la movilización social, a la libertad de expresión, a la apertura de otros horizontes culturales... que recorren la primavera en cuestión quedan lejos de tener un efecto homogéneo o de provocar un cambio decisivo. Todos esos elementos, además, preceden y suceden -"enmarcan" - una fecha que, según Glucksmann, "acelera simplemente un movimiento de larga duración, del que no se libra ningún país desarrollado" (Glucksmann, 2018: 96). Sin incurrir en contradicción, sí puede definirse en cambio, a su modo de ver, restrospectivamente Mayo del 68 como "la promesa de una revolución filosófica” (Glucksmann, 2018: 108) -todavía en marcha y por terminar-consistente en la progresiva autoconciencia de la desafección con respecto a la cultura revolucionaria proletaria-que es la que inspira, no obstante, las barricadas estudiantiles y la huelga obrera-. El presunto significado disruptivo de este acontecimiento quedaría de esta suerte reciclado como un gesto que todavía nada entre grandes relatos que cumplen, sin embargo, una función meramente retórica.

En una línea paralela, atenta al auge de la sociedad de consumo en la que el individuo se rinde al pragmatismo y se desentiende de causas superiores, discurre la reflexión de Lipovetsky. Para este autor, Mayo del 68 se integra en el proceso de privatización de la existencia que es indicativo de la evolución de la democracia que acompaña a la del capitalismo. Confluyendo con la cultura de masas, este culmina en una sensibilidad hedonista de acuerdo con la que todos los sujetos quieren formar parte del sistema, pero -lo que no deja de presentar una paradoja- para satisfacer de manera prioritaria sus propios placeres. En La era del vacio consigna en consonancia con ello un "nuevo estadio del individualismo" definido por el narcisismo (Lipovetsky, 1986: 50) ${ }^{17}$. De acuerdo con él, se impone un ideal

\footnotetext{
16 Para una revisión crítica de sus posiciones, véase, además de Ross, 2008, Cano, 2011: 81-114.

17 Lipovetsky prosigue el análisis en L'empire de l'éphémère. La mode et son destin dans les sociétés modernes (1987), donde se centra en la moda como culto a lo nuevo y en el hiperconsumo que define a las sociedades postmodernas.
} 
de autonomía personal que se reformula -nietzscheanamente- como un proyecto de autorrealización empeñado en el diseño íntimo y personal de las propias señas. A ello se ajusta una nueva economía subjetiva vertebrada por la exaltación del presente, la pérdida del sentido de la continuidad histórica y la obsesión por una novedad que se convierte en una repetición monótona.

Instalado en estos ejes, el sujeto heredero del sesentayochismo sería, en consecuencia, un individuo que, tras un -improductivo- momento de caos que no da a luz nada nuevo ni mejor, se centra en el cultivo del espacio privado y se reconoce en una voluntad hedonista plegada a la dinámica del consumo. En primera persona del singular, su autonomía se amplía y diversifica, pero también se trivializa sucumbiendo a las modas y tendencias. Siguiendo el hilo del presente trabajo, se trataría al final de una prolongación o versión del nihilismo pasivo al que se acomoda el último hombre contra el que clama Zaratustra. Y al respecto cabría plantearse si la inflexión nietzscheana de Mayo del 68 grabada en la pared del Odéon ha quedado sin ningún otro efecto o si puede servir todavía para alumbrar una estrella danzarina resistente tanto a la inmoralización advertida por Ferry y Renaut como a la banalización que se sanciona en los análisis de Glucksmann y Lipovetsky. En estos, como se apuntaba en la introducción, se aprecia un nietzscheanismo que, en la medida en que conserva el diagnóstico epocal hecho por el filósofo del martillo y no contempla su superación, se ha apellidado aquí -en este preciso sentido- libremente de derecha para facilitar el contraste con la lectura que propone Onfray.

Este último autor, en efecto, interpreta Mayo del 68 -y su posible culminación- en las coordenadas del explícitamente denominado "nietzscheanismo de izquierda" que adscribe a Foucault y Deleuze (Onfray, 2011: 155). A él atribuye el tono libertario en el que a su entender se condensa el éxito y la coherencia de lo que evoca esa fecha y que es representativo de la metafísica de la destrucción a la que antes ya se ha aludido: una impugnación de los argumentos tradicionales de autoridad que permite empoderar otro sujeto. A su modo de ver, "el individuo que hace su aparición en este Mayo constituye el paralelo político del nacimiento del Yo en la filosofía de Descartes" (Onfray, 2011: 149) ${ }^{18}$. Esa nueva figura, que no aspira -ni desea aspirar-al futuro radiante que prometía la utopía

18 También situando el significado de Mayo del 68 en la exigencia de libertad frente al autoritarismo y en la afirmación de la autonomía individual, discurre el planteamiento de Bruckner, Pascal (2008). "La tentation de l'individualisme". Le Magazine Littéraire, 13. 
teleológica clásica, quiere mantener su capacidad revolucionaria en otro sentido (Onfray, 2011: 193).

Y es Nietzsche, tal y como como lo actualiza Deleuze en la monografía antedicha, quien ofrecería la alternativa a la manera de pensar hegeliana reivindicando la autonomía a título personal y asumiendo, como se citaba más arriba, la afirmación de lo múltiple como postulado especulativo y el placer de lo diverso como postulado práctico. Multiplicidad y diversidad se erigen así en condiciones de posibilidad respectivas del conocimiento y de la moral que no pueden en ningún caso ajustarse a una fórmula unívoca de reconciliación. Por ello, el pensamiento nietzscheano "forma una antidialéctica absoluta" (Deleuze, 1986: 271). En la línea de la interpretación de Lefebvre, Deleuze reivindica un Nietzsche vitalista y por ello mismo subversivo, interesado en refutar el valor y la justificación que a la negatividad y al sufrimiento -a las "pasiones tristes" (Deleuze, 1986: 271)- le concede la hegemónica comprensión dialéctica de la realidad. El sentido, a su entender, sin embargo, no se descubre como reflejo de una totalidad en tortuoso progreso, sino que se produce individualmente en términos creativos y también antagonistas con respecto a la concepción moderno-liberal de la autonomía. En el itinerario hasta aquí recorrido, esta o bien diluye el yo en la universalidad -en la tónica de las demandas kantianas de Ferry y Renaut- o bien lo impulsa a una dinámica nihilista y consumista -como subrayan Glucksmann y Lipovetsky-. La propuesta de Onfray querría bloquear uno y otro extremo a favor de un individuo activado desde un punto de vista crítico.

Y ciertamente con esta impresión de una agencia moral insobornable en primera persona del singular -antes que con las consignas políticas clásicas-armonizarían muchas de las declaraciones de las paredes de Mayo del 68. En la facultad de Medicina, por ejemplo, se remitía la revolución a la liberación interior: "Construire une révolution c'est aussi briser les chaînes intérieures" (Besançon, 1968: 148). Y en el telón del Teatro del Odéon se trasladaba a la propia acción: " $L a$ révolution n'est pas seulement celle des comités mais avant tout la vôtre" (Besançon, 1968: 108). Los muros de Censier absolutizaban la autoridad de la primera persona del singular y exclamaban: "Ni maître, ni Dieu. Dieu c'est moi", "Ni robot, ni esclave", "Je ne suis au service de personne (pas même du peuple et encore moins de ses dirigeants)" (Besançon, 1968: 152, 67, 133). En la Sorbona se inscribía igualmente un yo que no quería estar a disposición de nadie: "Je ne suis au service de personne, le peuple se servira tout seul' (Besançon, 1968: 67). Se advertía también en la Rue Rotrou que el poder sobre la propia vida se obtiene de uno mismo: "Le pouvoir sur ta vie, tu le tiens de toi-même" (Besançon, 1968: 116). En 
Nanterre se animaba coherentemente a no expropiar el propio pensamiento: " $S i$ vous pensez pour les autres, les autres penseront pour vous" (Besançon, 1968: 87). $\mathrm{Y}$, en definitiva, entre pintada y pintada se respiraba un clima reacio a la perpetuación de una existencia alienada, monótona y aburrida, reducida en su trama principal a ir a trabajar y volver a dormir que se reconocía en el popular dicho "métro, boulot, dodo". Contra esta inercia -gesticulada como el parpadeo perplejo del último hombre-, se trataba de recuperar el poder de la imaginación, el azar y la creación. En la facultad de Ciencias políticas la lección mural era precisamente: "L'imagination prend le pouvoir" (Besançon, 1968: 146). Y en Censier podía en consonancia leerse: "Il faut systématiquement explorer le hasard" o "L'action ne doit pas être une réaction mais une création” (Besançon, 1968: 56).

En sintonía con este expresivo legado anónimo, la propuesta de Onfray subraya que la clave de la moralización de la sociedad radica en la del individuo: la ética individual ha de preceder al proyecto político ${ }^{19}$. La cita de Nietzsche que nos ha servido de pretexto para llegar a este punto compartía, de hecho, el espacio del Teatro del Odéon con una rotunda convicción al respecto: "Pour mettre en question la société où l'on "vit» il faut d'abord être capable de se mettre en question soi-même" (Besançon, 1968: 109). Ponerse en cuestión a si mismola: esta sería, por tanto, la tarea de formación de la propia subjetividad a la que se dedica el pensamiento nietzscheano con el fin de asegurar la oportunidad de poner en juego una perspectiva innovadora y no meramente reproductiva. Asumiendo esto, para el autor de Política del rebelde se trataría de articular un terreno intersubjetivo que pudiera colaborar en la desactivación de las lógicas del poder. Ello apunta así mismo a una nueva manera de concebir la relación entre la teoría y la práctica que facilita la aclaración del significado de Mayo de 68. Esta vía, en el marco de la discusión cartografiada en torno al individuo, conducirá a un balance a propósito de su capacidad de resistencia frente al statu quo.

\section{Individuo, poder y resistencia}

Tal y como coinciden en exponer Foucault y Deleuze, ambas esferas, la teórica y la práctica, mantienen relaciones parciales y fragmentarias, no pudiendo reducirse la segunda a la aplicación de la primera. Conforman un conjunto en movimiento que contiene "una multiplicidad de piezas y de pedazos" relevantes

\footnotetext{
19 La cuestión ha sido abordada por Onfray (1993).
} 
a la vez en ambos planos (Foucault, 2004: 24). Por ello, la acción se pluraliza al tiempo que se descentraliza, desechándose, por impersonal y vacío, el paradigma tradicional de la representación. Las fórmulas generales y las consignas estereotipadas quedarían igualmente descartadas frente a la afirmación de la multiplicidad y de la diversidad más arriba subrayada. Como consecuencia, el espacio de la política se abriría y reivindicaría inmediatez. Se trataría de introducir una acepción de revolución basada en el "devenir revolucionario de los individuos" (Onfray, 2011: 193). Con ello empatizaban las paredes de la facultad de Ciencias políticas cuando reivindicaban que "La politique se passe dans la rue, o las de la Sorbona cuando clamaban "Vive la démocratie directe" (Besançon, 1968: 35, 159). T. Negri afirma también en este sentido que Mayo del 68 supone la "llamada a una subversión creativa" caracterizada por el "pensamiento constitutivo", que ofrece -frente al "pensamiento de la mediación" que dependía de un esquema previamente dado- el sentido de la posibilidad, de producir una novedad no prevista (Negri, 1992: 42-43).

En esta línea, para Onfray el yo libertario congénito a Mayo del 68 es el que se exterioriza en las acciones particulares que tienen lugar en la calle, sobre los muros, en los lugares ocupados y en el intersticio de las conversaciones. Como se recordaba más arriba, el poder es coextensivo al cuerpo social, pero esto no implica que los individuos estén atrapados en su red de una manera absoluta. La dominación dibuja marcos generales y coherentes, que conviven, no obstante, no sólo con fenómenos de inercia, sino también de desfase y contestación. La resistencia coexiste con el poder, siendo ambos múltiples e integrables en diferentes estrategias (Foucault, 2004: 97ss.). Esta convicción permite pensar de otra manera las modalidades de insumisión y subversión, que, como las relaciones de dominación, no tienen una expresión específica y se ponen en circulación en los lugares más inimaginables. Asumiendo las lecciones de la biopolítica, Onfray concluye que "Mayo del 68 ha descubierto la difusión generalizada del poder y hace de éste, donde quiera que se encuentre, una ocasión de cuestionamiento, de crítica" (Onfray, 2011: 191).

Esta fecha quedaría, en consecuencia, ligada a una revisión de los marcos de dominación que se escenifican en la vida pública pero que vertebran, de idéntica forma, la vida privada. La puesta en cuestión de la normatividad -el caos dentro $s i$ - atañe así mismo al patriarcado y tiene un rendimiento feminista preciso que podría acompañarse de nuevo con una pintada: "Ma pensée n’est pas révolutionnaire si elle n'implique pas des actions quotidiennes dans le cadre éducatif familial et politique, et amoureux" (Besançon, 1968: 46). El pensamiento revolucionario 
ha de articularse, por tanto, en acciones cotidianas que intervienen también los esquemas familiares y afectivos. Con esta vocación concuerda el lema propuesto por K. Millet en 1970: lo personal es politico, que incide en el hecho de que el primer ámbito está igualmente sujeto a estructuras de poder que se han ido conformando y reconformando históricamente. Por ello, el trabajo crítico de cuestionamiento de sí -la formación de una subjetividad alternativa- ha de encaminarse también en esa dirección. Conviene al respecto reparar en que la mayoría de los nombres que aparecen en el escenario filosófico de Mayo del 68 -con la excepción de Beauvoir- son masculinos y no se detienen tampoco en esta consideración. Pero, aun así, la fecha puede ligarse al desarrollo del pensamiento feminista en la medida en que propicia una ampliación de la fenomenología de la resistencia y, subsiguientemente, de su agenda. Quizás esto sea una consecuencia impensada antes que un objetivo prioritario, pero justamente la principal enseñanza a extraer es que lo subversivo irrumpe así.

\section{A modo de conclusión}

Cruzar Mayo del 68 tirando del hilo del nietzscheanismo francés y con el pretexto de la frase de Asi habló Zaratustra citada en las paredes del Teatro del Odéon ha permitido reconstruir un capítulo de la discusión contemporánea a propósito del individualismo. Las diferentes figuras -inmoral, neonihilista, libertaria- a las que este se ha prestado de la mano de los autores aquí emplazados ha puesto de manifiesto la complejidad del debate y la imposibilidad de cerrarlo. No se trataba tampoco de medir la fidelidad de las referidas lecturas a Nietzsche, sino de advertir a través de ellas la actualidad de una perdurable -y resbaladiza- propuesta cuyo alcance polémico ha de ser el contexto de la conclusión. El filósofo del martillo sigue dando claves para componer una ontología crítica del presente, aunque su programa también debe mantenerse dentro de algunos límites. Sin embargo, frente al antinietzscheanismo sin matices de Ferry y Renaut cabría advertir que el pensador alemán no aspira a proporcionar una fórmula de organización socio-política interesada en socavar la democracia, sino a priorizar el sentimiento de la propia singularidad en la economía subjetiva. La nietzscheana es una ética de la diferencia -y no de la igualdad, ciertamente- pensada para resistir la gregarización, la falta de autenticidad que aqueja a las sociedades contemporáneas. Su preocupación es salvar para sí mismo a un individuo que se ve obligado a estar entre los demás - pero no contra ellos-. Esta voluntad, no obstante, no tendría por qué desembocar, por otra parte, en un paisaje neonihilista 
como el que dibujan Glucksmann y Lipovetsky y que seguiría prolongando el horizonte del último hombre, que es el que Zaratustra quiere superar. El individuo debería sortear la tentación del narcisismo y la lógica consumista con la que el neoliberalismo invade la propia dinámica constitutiva de la subjetividad. Y para ello también debería poder salvarse entre y con los demás, pues los marcos de dominación son en buena medida compartidos.

La concentración del trabajo moral en la primera persona del singular tendría que contemplar en algún momento su aportación a una gramática colectiva. No era este el tema de Nietzsche, que depositó una confianza excesiva en la capacidad del yo para reconciliarse hermenéuticamente con la propia biografía -para cultivar el amor fati-. Por ello, el nietzscheanismo de izquierda que Onfray liga a Mayo del 68 se hace productivo asumiendo la exploración del poder que llevan a cabo Foucault y Deleuze y que provee herramientas para pensar una noción polisémica de resistencia. Esta exige el ejercicio lúcido de la autonomía individual, que ha de ser consciente de que su margen depende también de lo que a cada cual, en la misma o diferente proporción que a los demás, se le impone y de lo que se puede a la vez oponer en común. Con las paredes y muros citados como propicia parada, pero más allá de este acotado escenario, esa noción podría ser la prometedora -y siempre frágil- estrella danzarina que ayudó a divisar Nietzsche y que, contra los límites de su propia propuesta, todavía tiene sitio en nuestro horizonte.

\section{Bibliografía}

Bantigny, Ludivine (2018). 1968. De grands soirs en petits matins. París: Éditions du Seuil.

Bello, Eduardo (2010). "Mayo del 68: Utopía y realidad". En Nájera, Elena y Pérez Herranz, Fernando M. (ed.). La filosofía y la identidad europea. Valencia: Pre-Textos.

Besançon, Julien (1968). Les murs ont la parole. Journal Mural Mai 68. París: Tchou. Bruckner, Pascal (2008). "La tentation de l'individualisme". Le Magazine Littéraire, 13. 
Cano, Germán (2011). "La vida en juego. Mayo del 68 como laboratorio biopolítico". En Cereceda, Miguel y Velasco, Gonzalo (ed.). El pensamiento político de la comunidad a partir de Roberto Espósito. Madrid: Arena Libros.

Deleuze, Gilles (1986). Nietzsche y la filosofía. Barcelona: Anagrama.

Descombes, Vincent. (1991). "Le moment français de Nietzsche”. En VV. AA. (1991). Pourquoi nous ne sommes pas nietzschéens. París: Éditions Grasset.

Ferry, Luc et Renaut, Alain (1985). La pensée 68. Essai sur l'anti-humanisme contemporain. París: Éditions Gallimard.

- (1991). "Ce qui a besoin d'être démontré ne vaut pas grand-chose” En VV. AA. Pourquoi nous ne sommes pas nietzschéens. París: Éditions Grasset.

Foucault, Michel (1998). Historia de la locura en la época clásica. México: FCE.

- (2004). Un diálogo sobre el poder. Madrid: Alianza Editorial.

Glucksmann, André y Raphä̈l (2018). Mayo del 68. Por la subversión permanente. Madrid: Taurus.

Hess, Rémi (1988). Henri Lefebvre et l'aventure du siècle. Paris: A. M. Métailié.

Lecourt, Dominique (1999). Les Piètres penseurs. París: Flammarion.

Lefebvre, Henri (1939). Nietzsche. París: Éditions sociales internationales.

- (1973). La violencia y el fin de la historia. Buenos Aires: Ediciones Siglo XX.

- (1976). Hegel, Marx, Nietzsche (o el reino de las sombras). Madrid: Siglo XXI.

Lipovetsky, Gilles (1986). La era del vacio. Ensayos sobre el individualismo contemporáneo. Barcelona: Anagrama, Barcelona.

- (1987). L'empire de l'éphémère. La mode et son destin dans les sociétés modernes. París: Folio.

Millet, Kate (1970). Sexual Politics. Chicago: University of Chicago Press.

Morin, Edgar; Lefort, Claude et Castoriadis, Cornelius (2008). Mai 68: La brèche, suivi de Vingt ans après. París: Fayard.

Nájera, Elena (2018). "Vivir en medio del hielo. Resistencia y escepticismo en El Anticristo”. Logos. Anales del Seminario de Metafísica, 51, 283-303. http://dx.doi. org/10.5209/rev_RASO.2016.v24.1.50642

Negri, Toni (1992). Fin de siglo. Barcelona: Paidós.

Nietzsche, Friedrich (1994). Asi habló Zaratustra. Madrid: Alianza Editorial.

- (1996). Crepúsculo de los ídolos. Madrid: Alianza Editorial.

- (1999). Sämtliche Werke. Kritische Studienausgabe in 15 Bänden (KSA), 15 vols.

Berlín-Nueva York: Walter de Gruyter (ed. de G. Colli y M. Montinari). 
- (2000). Sobre el porvenir de nuestras escuelas. Barcelona: Tusquets.

- (2011). La ciencia jovial. Madrid: Biblioteca Nueva.

Onfray, Michel (1993). La Sculpture de soi. París: Grasset.

- (2011). Politica del rebelde. Tratado de resistencia e insumisión. Barcelona: Anagrama.

Renaut, Alain (1989). L'Ére de l'individu. Contribution à une histoire de la subjectivité, París: Gallimard.

- (1998). "Les subjectivités: pour une histoire du concept de sujet". En VV. AA. Penser le sujet aujourd'hui. París: Méridiens Klincksieck.

Rivera de Rosales, Jacinto (2012). "Un poco de caos para alumbrar una estrella danzarina. Nietzsche y el espíritu trágico”. Convivium, 25, 115-144.

Ross, KRIstin (2008). Mayo del 68 y sus vidas posteriores. Madrid: Ediciones Acuarela. VV. AA. (1967). Nietzsche (Cahiers de Royaumont). París: Les Éditions de Minuit.

VV. AA. (2008). Mai 68, Le Débat. París: Éditions Gallimard.

Recibido: 23/12/2018

Aceptado: 6/06/2019

Este trabajo se encuentra bajo una licencia de Creative Commons ReconocimientoNoComercial-SinObraDerivada 4.0 